\title{
An Empirical Model for the lonospheric Global Electron Content Storm-Time Response
}

\author{
Shuhui $\mathrm{LI}^{1}$, Roman GALAS ${ }^{2}$, Dietrich EWERT ${ }^{2}$, and Junhuan PENG ${ }^{1}$ \\ ${ }^{1}$ School of Land Science and Technology, \\ China University of Geosciences (Beijing), Beijing, China; \\ e-mails: li.shuhui@163.com (corresponding author),pengjunhuan@163.com \\ ${ }^{2}$ Department for Geodesy and Geoinformation Sciences, \\ Technische Universität Berlin, Berlin, Germany; \\ e-mails: roman.galas@tu-berlin.de,dr.ewert@yahoo.de
}

\begin{abstract}
By analyzing the variations of global electron content (GEC) during geomagnetic storm events, the ratio " $\mathrm{GEC} / \mathrm{GEC}_{\mathrm{QT}}$ " is found to be closely correlated with geomagnetic $K p$ index and time weighted $D s t$ index, where $\mathrm{GEC}_{\mathrm{QT}}$ is the quiet time reference value. Moreover, the $\mathrm{GEC}_{\mathrm{GEC}} \mathrm{GT}_{\mathrm{QT}}$ will decrease with the increase of the solar flux F10.7 index. Furthermore, we construct a linear model for storm-time response of GEC. Eighty-two storm events during 1999-2011 were utilized to calculate the model coefficients, and the performance of the model was tested using data of 8 storm events in 2012 by comparing the outputs of the model with the observed GEC values. Results suggest that the model can capture the characteristics of the GEC variation in response to magnetic storms. The component describing the solar activity influence shows a counteracting effect with the geomagnetic activity component; and the influence of $K p$ index causes an increase of GEC, while the time weighted Dst index causes a decrease of GEC.
\end{abstract}

Key words: ionosphere, GEC, geomagnetic $K p$ index, time-weighted geomagnetic Dst index, empirical model.

Ownership: Institute of Geophysics, Polish Academy of Sciences;

(C) $2015 \mathrm{Li}$ et al. This is an open access article distributed under the Creative Commons Attribution-NonCommercial-NoDerivs license,

http://creativecommons.org/licenses/by-nc-nd/3.0/. 


\section{INTRODUCTION}

Ionosphere, the Earth's upper atmosphere, is a part containing atoms that have been ionized by radiation from the Sun. It will show different behavior with the change of solar activity and input of magnetosphere energy (FullerRowell et al. 1994, Forbes et al. 2000, Afraimovich et al. 2006a, Jakowski et al. 2006, 2008; Stankov et al. 2006, Trichtchenko et al. 2007, Liu et al. 2011). The investigation of the inherent characteristics and rules of variations in ionosphere is important to the field of ionospheric physics and the correction of electromagnetic wave refraction.

During magnetic storms, the energy input of geomagnetic activity causes enhanced electric fields, currents, and energetic particle precipitation. The state of ionosphere will change greatly (Buonsanto 1999, Tsagouri et al. 2000, Prölss 2006, Gulyaeva and Stanislawska 2008). Many researchers studied the morphology of ionosphere during geomagnetic storms, and have constructed some models to describe the response pattern. Araujo-Pradere and Fuller-Rowell (2000) developed an empirical formula to account for the summer hemisphere mid-latitude ionospheric response as a definition of the time history of the previous 30 hours of the TIROS/NOAA power index (or $A p$ index) weighted by a filter. Araujo-Pradere et al. (2002) established an empirical model of a perturbed ionosphere (STORM) to predict $F$-layer critical frequency $(f o F 2)$ utilizing the integral of the $A p$ index over the previous 33 hours weighted by a filter obtained by the method of singular value decomposition; the model coefficients change with different seasons and latitudes. Wang et al. (2008) adapted a linear model of Dst index to present the characteristic of ionospheric $f o F 2$ responses to geomagnetic activities in different seasons and under different levels of solar activity. Pietrella and Perrone (2008) put forward a local model to predict foF2 measured in Rome; time weighted $A p$ index is the input parameter in the study. Tsagouri and Belehaki (2008) examined the ionospheric $f o F 2$ response at middle-to-high and middle-to-low latitudes in each local time sector modeled by a 6th degree polynomial function. Berdermann et al. (2012) studied the vertical total electron content (TEC) prediction method during geomagnetic disturbances over Europe with a model considering storm level, onset time, and local time. All the results of related researches prove the dependence of the ionosphere parameters on the season, latitude and local time.

In recent years, with the benefit of global monitoring of Global Positioning System (GPS), numerous researches have introduced global or regional averaged ionospheric TEC parameters to study the climatology variation of ionosphere. The principal advantage of these parameters is that they can capture the overall ionospheric features and greatly depress local noises in the ionosphere (Astafyeva et al. 2008, Liu et al. 2009). Xu et al. (2008) exam- 
ined the relationship between ionosphere and the tropospheric circulation around the Qinghai-Tibet Plateau using a mean TEC over East Asia. Liu et al. (2009) compared averaged TEC over low-, middle-, and high-latitude ranges to get the characteristic under different solar activities and seasons. Lean et al. (2011) utilized the global daily averaged TEC to analyze the influence of solar activity, geomagnetic activity, and the periodic variation of the ionosphere. TEC is described with a linear model, accounting simultaneously for the influences of solar and geomagnetic activity, oscillations at four frequencies and a secular trend. In Lean et al. (2011)'s study, previous 1 day $A p$ index is used to present the geomagnetic activity. In order to compare influence of different impact factors in different latitudes, Li et al. (2013) analyzed the daily averaged TEC over different latitudes along meridian $115^{\circ} \mathrm{E}$, and it was shown in Li et al. (2013) that the time series model in consideration of the geomagnetic activity $A p$ index can reflect the response of daily averaged TEC to magnetic disturbance with variation characteristics. Bergeot et al. (2013) analyzed the time series of regional averaged TEC over different latitude (TDM-TEC), considered to be able to change $19.6 \pm 15.0 \%$ during the magnetic storm.

Afraimovich et al. (2006b) firstly introduced the concept of global electron content (GEC), which is equal to the total numbers of electrons in the near-Earth space and could present the average variation of the global ionosphere for climatological analysis. Afraimovich et al. (2008) researched the variation of GEC during solar cycle 23; the results showed that the GEC dynamics followed similar variations in the solar UV irradiance and $F 10.7$ index, including the 11-year cycle and 27-day variations. She et al. (2008) calculated equivalent GEC from GPS TEC data along the geographic longitude $120^{\circ} \mathrm{E}$ and investigated the relationship between the equivalent GEC and solar F10.7 index. The results suggested that the equivalent GEC mainly depends on solar activity and the seasonal variations. Furthermore, the magnitude of semiannual variation is a little greater than that of annual variation. Gulyaeva and Veselovsky (2012) developed an analytical model of twophase GEC storm profile in terms of the peak DGEC departures from the quiet reference and time of the storm in progress. The results showed that the GEC takes the proper place as a proxy of the global parameter for the plasmasphere-ionosphere segment of the Earth's space environment. Using the GEC parameter, researcher can get an overall rule and characteristic of global ionosphere without considering the local time and season influence. By now, the dependence of GEC on solar activity has been studied in detail; however, the response and variation of GEC due to the magnetic storm remains a subject for in-depth investigation.

For the present study, we chose to investigate the characteristic of global ionosphere during geomagnetic storm using GEC values during 90 storm 
events in the years from 1999 to 2012 (Appendix). An empirical linear model was developed and its performance evaluated in this article. The influence of different factors on the modelled GEC was also investigated and presented in this paper.

\section{DATA}

International GNSS Service (IGS) uses ground-based GNSS observations to routinely generate ionosphere TEC data through IONEX formatted global ionosphere maps (GIMs), which are available through the website ftp:// cddisa.gsfc.nasa.gov/pub/gps/products/ionex/. The TEC values are given in GIM cells with 2-hour resolution. The size of a GIM cell is $5^{\circ}$ along the longitude and $2.5^{\circ}$ along the latitude. Ionospheric GEC $G$ is calculated by summation of TEC values in each GIM cell multiplied by the GIM cell area over all GIM cells (Afraimovich et al. 2006b). The unit of GEC is GECU; $1 \mathrm{GECU}=10^{32}$ electrons.

$$
G=\sum S_{i, j} I_{i, j},
$$

where $i, j$ are the indices of the GIM cell; $I_{i, j}$ is the vertical TEC value over the GIM cell, the unit of TEC is TECU, and 1 TECU $=1.0 \times 10^{16}$ electrons $\cdot \mathrm{m}^{-2} ; S_{i, j}$ is the area of the GIM cell, it can be written as

$$
S_{i, j}=R_{E}^{2} \Delta \varphi\left[\sin \theta_{j}-\sin \left(\theta_{j}+\Delta \theta\right)\right],
$$

where $\Delta \varphi$ is the variation range in latitude, $\theta_{j}$ is the longitude, $\Delta \theta$ is the variation range in longitude; $R_{E}$ is the radius of ionosphere shell, to which we set here a value of $6771.004 \mathrm{~km}$ (She et al. 2008).

The instantaneous variation in GEC due to the storm can be reflected by index $R_{\mathrm{GEC}}$, which is defined as the ratio of GEC observation and the GEC reference value at quiet time $\mathrm{GEC}_{\mathrm{QT}}$ as follows

$$
R_{\mathrm{GEC}}=\mathrm{GEC} / \mathrm{GEC}_{\mathrm{QT}} \text {. }
$$

The value of $\mathrm{GEC}_{\mathrm{QT}}$ can be chosen as the median value or average value of GEC during several days with quiet geomagnetic activity (Zhao et al. 2007, 2008; Liu et al. 2009, Stankov et al. 2010, Berdermann et al. 2012). Ratio value $R_{\mathrm{GEC}}$ has no unit, so it is convenient to compare the GEC variation under different levels of geomagnetic storm and solar activity. In this study, we chose 6 quiet days' smoothed average GEC as the quiet time reference value $\mathrm{GEC}_{\mathrm{QT}}$. A quiet day is judged by the geomagnetic $K p$ index with the condition $0=<K p<3.0$.

The well-known indices $K p$ and $D s t$ were chosen to represent the geomagnetic activity in this study (The Dst index data is available at http://wdc. 
kugi.kyoto-u.ac.jp, and the $K p$ index data is available at http://www.ngdc. noaa.gov/stp/GEOMAG/Kp_ap.html). $K p$ index has 3-hour bins of time, $D s t$ index has 1-hour bins, and GEC has 2-hour bins. In this study, we selected the 2-hour interval $K p$ and $D s t$ indice values at the same hour with GEC data for analysis, assuming that the $K p$ index is the same during the 3-hour period. Furthermore, the time weighted geomagnetic index is also used in this study. Wrenn (1987) first introduced the time weighted geomagnetic index. Researches proved that it can reflect the accumulated influence of geomagnetic activity in history (Wu and Wilkinson 1995, Perrone et al. 2001). For a given geomagnetic index $\Gamma$, time weighted index $\Gamma(\tau)$ is defined as

$$
\Gamma(\tau)=(1-\tau)\left[\Gamma_{0}+\tau \Gamma_{-1}+\tau^{2} \Gamma_{-2}+\ldots\right],
$$

where geomagnetic index $\Gamma$ may be $K p$, Dst or $A p$ index, etc.; time delay $\tau$ can be given as a fraction between 0.7 and 0.95 . The larger the value $\tau$ is, the stronger the dependence of $\Gamma(\tau)$ on the history information will be. The time weighted value $\Gamma(\tau)$ is the comprehensive influence of previous geomagnetic indices over a period, such as 24 or 48 hours. At the certain time $t_{0}$, the geomagnetic is $\Gamma_{0}$, and the $\Gamma_{-1}$ and $\Gamma_{-2}$ are the first and second previous values.

Based on the interplanetary magnetic field (IMF) observations, we determined the onset time of every storm event during the period of 1999 to 2012. The variations of IMF are considered the triggering point of a storm event. As discussed by Tsagouri and Belehaki (2008), the conditions to judge a storm event included: (i) the IMF- $B$ should record either a rapid increase denoted by time derivative values greater than $3.8 \mathrm{nT} / \mathrm{h}$ or absolute values greater than $13 \mathrm{nT}$; (ii) the IMF- $\mathrm{Bz}$ component should be southward directed either simultaneously or a few hours later (e.g., $6 \mathrm{~h}$ ); and (iii) the event ends when $B z$ is turned northward $(B z>-1 \mathrm{nT})$. The IMF observations are available at http://omniweb.gsfc.nasa.gov.

\section{MODELING AND ANALYSIS OF GEC RESPONSE TO MAGNETIC STORMS}

\subsection{Behavior of ionosphere GEC in response to geomagnetic storm}

Referring to the variation of IMF, 90 storm events during the period of 19992012 were determined in this paper. Figure 1 shows the numbers of storm events in different years and seasons. Figure $1 \mathrm{~b}$ also illustrates the level of storm events according to three degrees: (i) moderate intensity (minimum Dst $>-100 \mathrm{nT}$ ), (ii) intense (minimum Dst between -100 and $-200 \mathrm{nT}$ ), and (iii) extreme (minimum $D s t$ below $-200 \mathrm{nT}$ ). The maximum phase of $23 \mathrm{rd}$ solar cycle was during 2000-2002, and the period of 2006-2008 is the mini- 

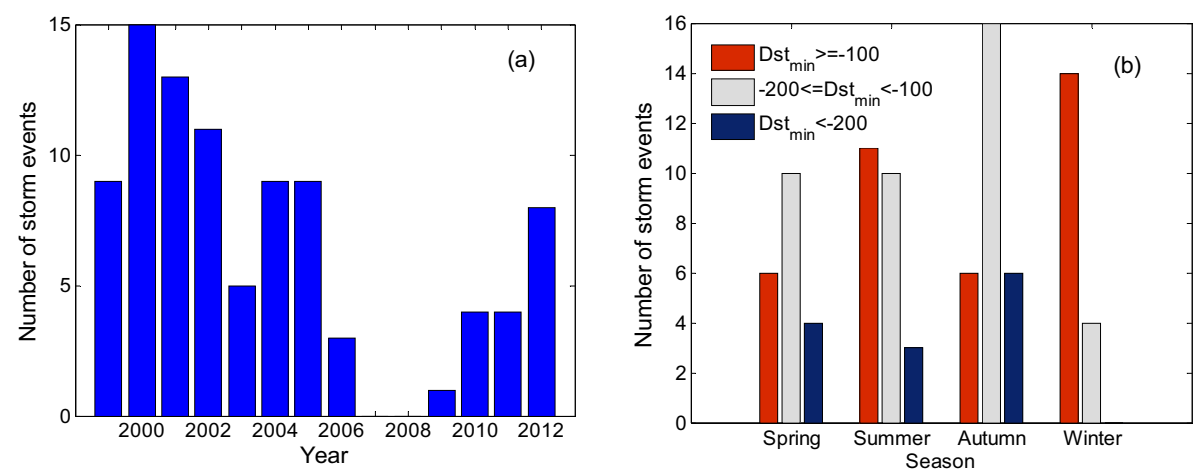

Fig. 1. Number of geomagnetic storm events for the period 1999-2012 based on interplanetary magnetic field (IMF) data: (a) distribution in different years, (b) distribution in different seasons of the Northern Hemisphere.

mum phase of the solar cycle. From Fig. 1 we can see that the occurrence rate of storm events is proportional to solar activity, and intense and big storm events taking place in the autumn season of the Northern Hemisphere have a big proportion.

The correlation coefficient of $R_{\mathrm{GEC}}$ and different geomagnetic indices in every storm event were calculated in the study; the geomagnetic indices include $K p, D s t$, and $A p$ index as well as their corresponding time weighted values $K p(\tau), \operatorname{Dst}(\tau)$, and $A p(\tau)$. All the combinations of time delay $\tau$ and time span of history information are compared respectively, where $\tau$ is chosen from $0.7,0.75, \ldots, 0.95$, the time span is chosen from the previous 24 or 48 hours. Results show that $R_{\mathrm{GEC}}$ is closely correlated with $\operatorname{Dst}(\tau=0.95)$ considering previous 24 hours information, then is the geomagnetic $K p$ index. The study of Wu and Wilkinson (1995) indicated that $\tau$ can be selected from 0.9 to 0.95 when calculating $\operatorname{Dst}(\tau)$ to present the influence of earlier geomagnetic activity. Figure $2 \mathrm{a}$ shows the correlation coefficients of $R_{\mathrm{GEC}}$ and the two geomagnetic indices. In addition, the correlation coefficient of $R_{\mathrm{GEC}}$ and $K p$ will always be high when the correlation coefficient of $R_{\mathrm{GEC}}$ and $\operatorname{Dst}(\tau=0.95)$ is relatively low, which can be seen in Fig. $2 \mathrm{~b}$. The time weighted geomagnetic index $\operatorname{Dst}(\tau=0.95)$ presents the accumulated influence of geomagnetic activity for a period of previous 24 hours, while the $K p$ index reflects the current 3 -hour activity level. In general, the correlation coefficients of $R_{\mathrm{GEC}}$ and $\operatorname{Dst}(\tau=0.95)$ are large on the event of long disturbance geomagnetic storm. However, the correlation coefficient of $R_{\mathrm{GEC}}$ and $K p$ index will be large if the geomagnetic activity recovers to quiet level soon after the storm onset. Therefore, it is necessary to consider the geomagnetic $K p$ index together with the time weighted $\operatorname{Dst}(\tau=0.95)$ index to examine the GEC response to geomagnetic storm. 
(a)

(b)
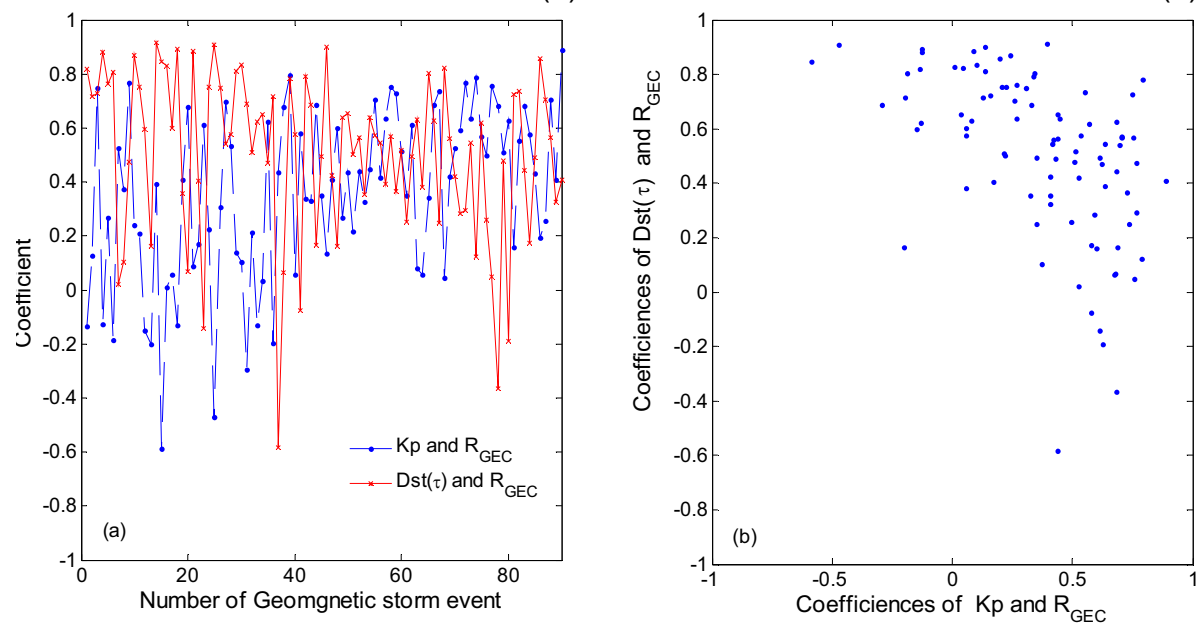

Fig. 2. During the 90 storm events from 1999 to 2012: (a) correlation coefficients of $R_{\mathrm{GEC}}$ and $K p$ index and that of $R_{\mathrm{GEC}}$ and $\operatorname{Dst}(\tau=0.95)$ index, and (b) scatter plot of the two correlation coefficients. The $x$-axis shows the correlation coefficient between $R_{\mathrm{GEC}}$ and $K p$ index, and the $y$-axis shows the correlation coefficient between $R_{\mathrm{GEC}}$ and $\operatorname{Dst}(\tau=0.95)$ index.

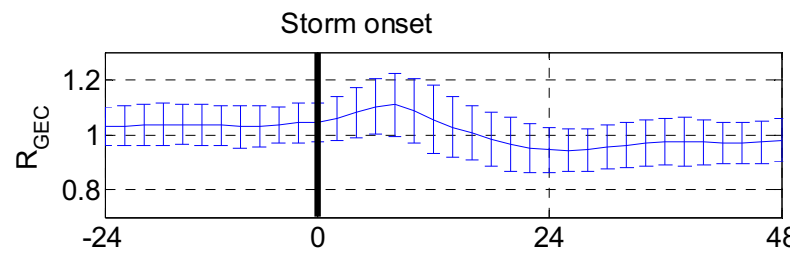

(a)

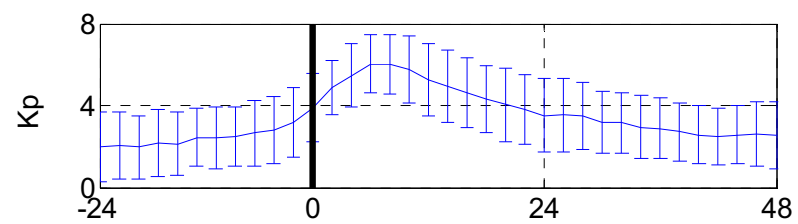

(b)

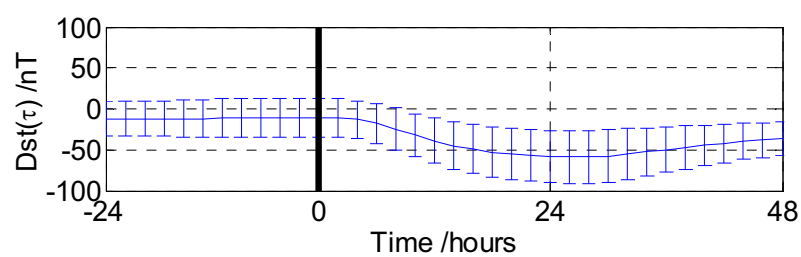

(c)

Fig. 3. Averaged variation of ionospheric GEC and geomagnetic indices during 90 storm events: (a) $R_{\mathrm{GEC}}$, (b) $K p$ index; and (c) $\operatorname{Dst}(\tau=0.95)$. The error bar in the figure is standard deviation, and the bold line is the time of storm onset. 


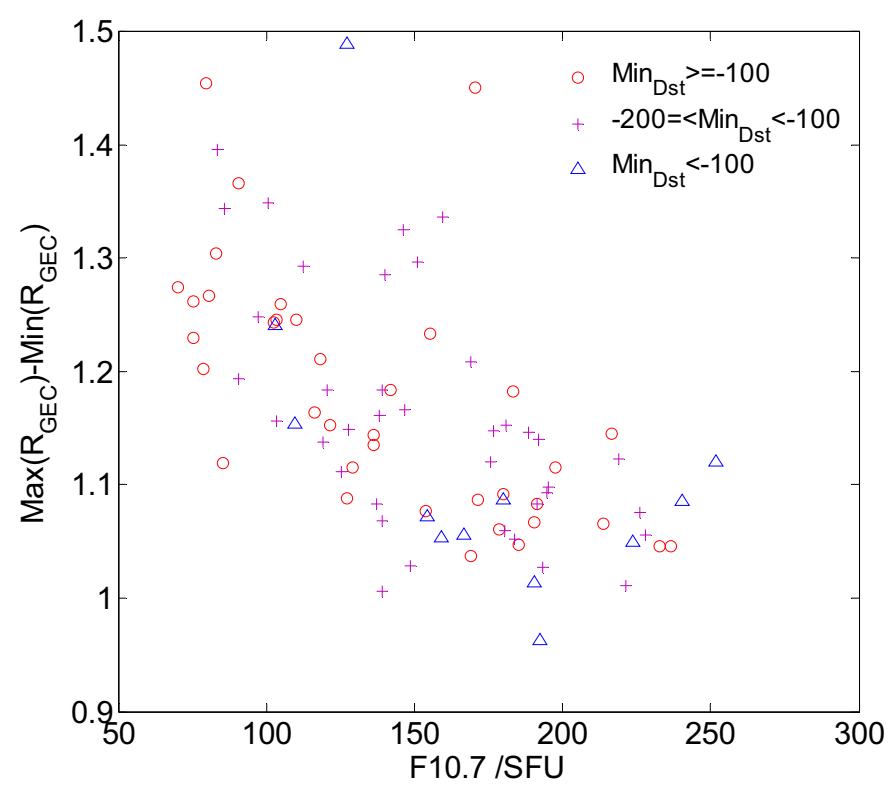

Fig. 4. Relationship of solar $F 10.7$ index and the variation range of $R_{\mathrm{GEC}}$, namely, $\operatorname{Max}\left(R_{\mathrm{GEC}}\right)-\operatorname{Min}\left(R_{\mathrm{GEC}}\right)$.

Average patterns in the GEC behavior during the 90 storm events were deduced, with the results shown in Fig. 3. Three-day $R_{\mathrm{GEC}}$ values which include data one day before storm onset, and two days after the storm onset were under consideration. As the GEC is calculated with the 2-hour resolution TEC values from GIMs, the amount of $R_{\mathrm{GEC}}$ values here is 36 . After the storm onset, the $R_{\mathrm{GEC}}$ starts to increase, and shortly after the peak, $R_{\mathrm{GEC}}$ decreases to a negative minimum value, and then slowly recovers again until approaching the quiet time value of 1 . Variation and behavior of $R_{\mathrm{GEC}}$ clearly show the evolution of the positive phase and negative phase compared to the quiet time. In the study by Stankov et al. (2010), the storm-time behaviour of TEC also shows the evolution of both the positive and negative phases, in comparison with the quiet-time behaviour, with amplitudes tending to increase during more intense storms.

Besides, we compared the $R_{\mathrm{GEC}}$ values with different solar $F 10.7$ index level. It was found that the variation range of $R_{\mathrm{GEC}}$ will decrease with the increase of the solar F10.7 index, which can be seen from Fig. 4. Regarding this situation, some studies modeled the ionospheric parameter in different groups according to different $F 10.7$ level (Pietrella and Perrone 2008). In this article, we take the solar $F 10.7$ index into account in the GEC response model. 


\subsection{Empirical response model of ionospheric GEC to geomagnetic storm}

In this article, for a given time $t, R_{\mathrm{GEC}}(t)$, the ratio of GEC and the reference value of quiet time $\mathrm{GEC}_{\mathrm{QT}}$, is expressed by a linear function of geomagnetic activity and solar activity as follows

$$
R_{\mathrm{GEC}}(t)=c_{0}+F_{1}(t)+F_{2}(t),
$$

where $c_{0}$ is a constant, $F_{1}(t)$ is the component related to geomagnetic activity, and $F_{2}(t)$ is the component considering the solar activity level together with geomagnetic activity. $F_{1}(t)$ is defined as

$$
F_{1}(t)=c_{1} k p(t)+c_{2} k p(t)^{2}+c_{3} D s t_{\tau}(t)+c_{4} D s t_{\tau}(t)^{2}+c_{5} k p(t) D s t_{\tau}(t),
$$

where $c_{\mathrm{i}}$ is the coefficients of the model, $i=1,2, \ldots, 5 ; \mathrm{kp}(t)$ is the geomagnetic $K p$ index at time $t ; D s t_{\Gamma}(t)$ is the time weighted $D s t$ index, and $\tau$ is equal to $0.95 . F_{2}(t)$ is defined as follows

$$
F_{2}(t)=\left[c_{6} k p(t)+c_{7} k p(t)^{2}+c_{8} D s t_{\tau}(t)+c_{9} D s t_{\tau}(t)^{2}+c_{10} k p(t) D s t_{\tau}(t)\right] f_{10.7}(t),
$$

where $c_{i}$ is the coefficient of the model, $i=6,7, \ldots, 10 ; f_{10.7}(t)$ is the solar radiation flux $F 10.7$ index on that day.

Based on the quiet time reference value $\mathrm{GEC}_{\mathrm{QT}}$ and the value of $R_{\mathrm{GEC}}$ from Eq. 5, we can calculate the ionospheric GEC at time $t$.

$$
\operatorname{GEC}(t)=\operatorname{GEC}_{\mathrm{QT}}(t) R_{\mathrm{GEC}}(t) .
$$

The coefficients of the model were calculated by the least squares method. Here, 82 storm events in the years from 1999 to 2011 were used to calculate the coefficients. Figure 5 shows the scatter plot of the observed GEC and the modeled results; we can see the agreement of the two time series. Figure 6 shows the histogram of the residuals of the modeled results; the statistical error clearly exhibits a normal distribution. We therefore conclude that the constructed model is possible to represent GEC variation in case of storm event.

The GEC data during 8 storm events in 2012 were utilized to test the performance of the model. The results are shown in Fig. 7. It is to be noted that these data have not been used in the determination of the model coefficients. From Fig. 7 we can see the variation of observed and the fitted results of GEC during a period of 3 days, namely one day before and two days after the storm onset. The correlation coefficient $R$ is between 0.59 and 0.89 , and the fitted standard deviation $\sigma$ is between 0.05 and 0.08 GECU. Using the empirical model, we can estimate the GEC variation during storms. 


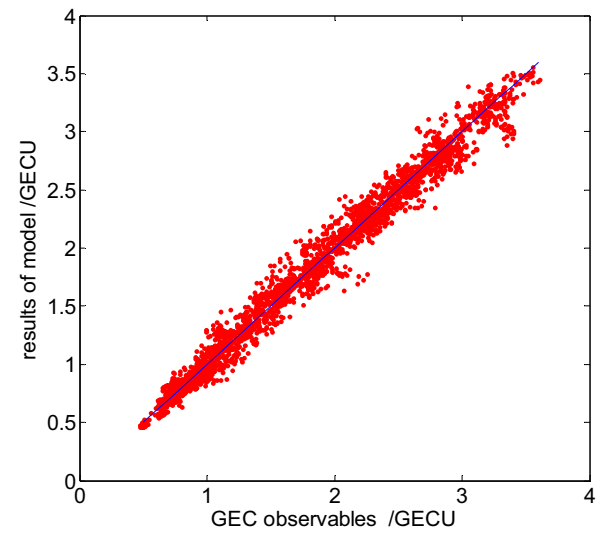

Fig. 5. Scattergram of GEC observables and results of model.
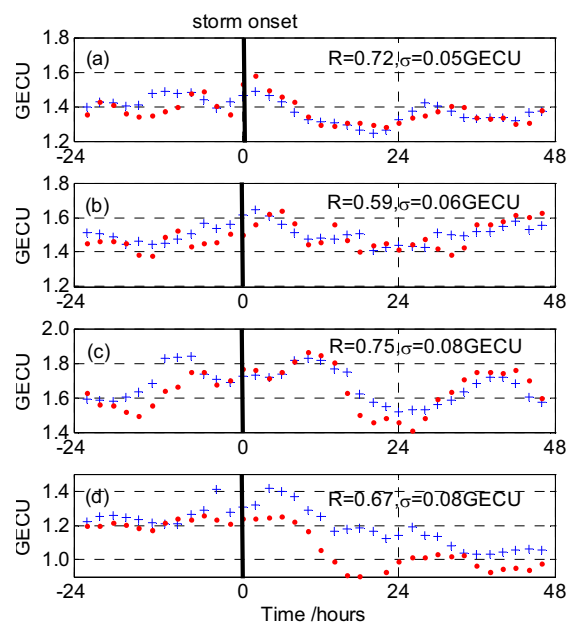

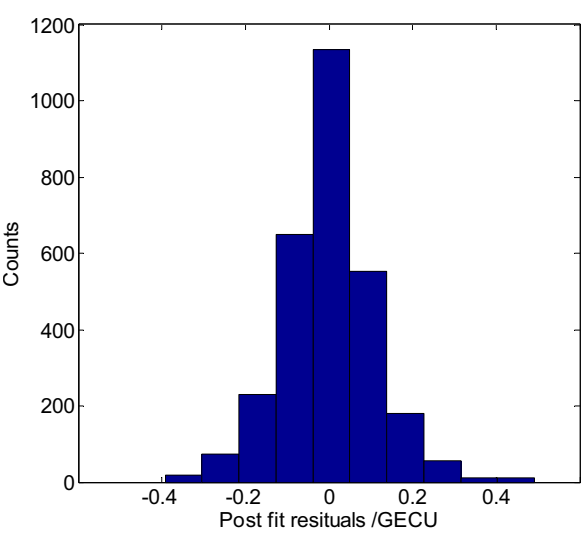

Fig. 6. Histogram of post-fit residuals of GEC.
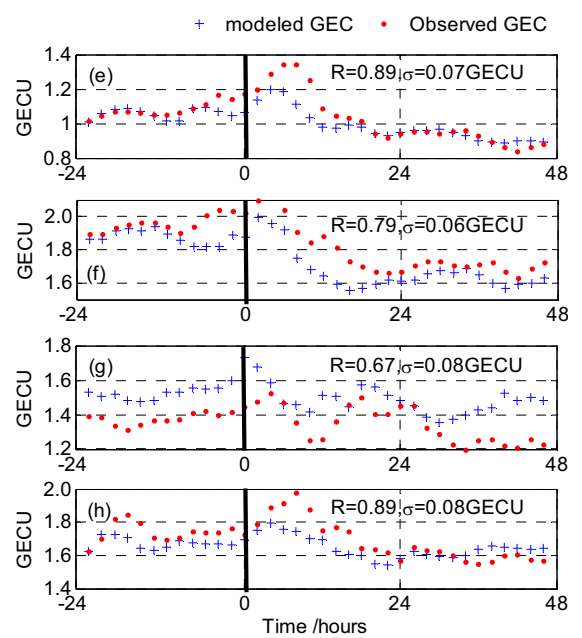

Fig. 7. Observed GEC and fitted result of the model during 8 storm events in 2012. The bold line denotes the time of storm onset, $R$ is the correlation coefficient, and $\sigma$ is the standard deviation. The day of year (Doy ) and the UT time of every storm event are as follows: (a) Doy 22, 20:00 UT; (b) Doy 67, 04:00 UT; (c) Doy 114, 16:00 UT; (d) Doy 169, 02:00 UT; (e) Doy 197, 02:00 UT; (f) Doy 274, 23:00 UT; (g) Doy 282, 06:00 UT; and (h) Doy 318, 20:00 UT.

The empirical model of the GEC response to geomagnetic storms is not related to the exact time of the storm onset, hence the accuracy of the time of storm onset will not affect the GEC result. We determined the time of storm onset in this study aiming to get a better statistical analysis of the rule and pattern of GEC response to the storm event. There are many different meth- 
ods to determine the time of storm onset, except for the method based on the IMF observations change in this study. For example, the change of Dst index is used as a criterion in many researches (Stankov et al. 2010, Berdermann et al. 2012). However, for many storm events, the time of onset determined by different methods differs greatly. So an empirical model which does not include the factor of time after storm onset will prevent the problem with the error of determination of storm onset.

\subsection{Influence of different factors on GEC variation in response to geomagnetic storm}

The constructed linear model was utilized to assess to what degree the variability may be attributed to various sources. Firstly, we defined two components of GEC variation. One is the influence of geomagnetic activity as $F_{\mathrm{GEO}}(t)$, and the other is the integrity influence of geomagnetic and solar activity as $F_{\text {SOL }}(t)$, namely,

$$
\begin{aligned}
& F_{\mathrm{GEO}}(t)=F_{1}(t) G E C_{\mathrm{QT}}(t), \\
& F_{\mathrm{SOL}}(t)=F_{2}(t) G E C_{\mathrm{QT}}(t) .
\end{aligned}
$$

Secondly, for the two geomagnetic activity indexes, $K p$ and $D s t(t)$, we defined influence of $K p$ index as $F_{K p}$, the influence of time weighted $\operatorname{Dst}(\tau)$ index as $F_{D s t(\Gamma)}$, as well as the integrated influence of the two indices as $F_{K p, D s t(\Gamma)}$.

$$
\begin{aligned}
& F_{K p}=\left\{c_{1} k p(t)+c_{2} k p(t)^{2}+\left[c_{6} k p(t)+c_{7} k p(t)^{2}\right] f_{10.7}(t)\right\} G E C_{\mathrm{QT}}(t), \\
& F_{D s t(\tau)}=\left\{c_{3} D s t_{\tau}(t)+c_{4} D s t_{\tau}(t)^{2}+\left[c_{8} D s t_{\tau}(t)+c_{9} D s t_{\tau}(t)^{2}\right] f_{10.7}(t)\right\} G E C_{\mathrm{QT}}(t), \\
& F_{K p, D s t(\tau)}=\left[c_{5} K p(t) D s t_{\tau}(t)+c_{10} K p(t) D s t_{\tau}(t) f_{10.7}(t)\right] G E C_{Q T}(t) .
\end{aligned}
$$

Figure 8 shows the influence of geomagnetic activity $F_{\mathrm{GEO}}(t)$ and the integrated influence of geomagnetic and solar activity $F_{\text {SOL }}(t)$, respectively. From Fig. 8a, we can see that the influence of geomagnetic activity has appeared before the storm onset. $F_{\mathrm{GEO}}(t)$ illustrates the evolution of the positive phase and negative phase in GEC. Compared with the decreased value of negative phase, the increase of GEC is relatively greater. The values of $F_{\mathrm{SOL}}(t)$ shown in Fig. $8 \mathrm{~b}$ are always opposite. If $F_{\mathrm{GEO}}(t)$ is a relatively larger positive value, $F_{\mathrm{SOL}}(t)$ will be a greater negative value. So the $F_{\mathrm{SOL}}(t)$ has a counteractive effect on the component of geomagnetic activity.

Figure 9 shows the extent and the variation of three components: the influence of geomagnetic $K p$ index $F_{K p}$, the influence of time weighted $\operatorname{Dst}(\tau)$ index $F_{D s t(\Gamma)}$, and the integrated influence of the two factors $F_{K p, D s t(\Gamma)}$. From 

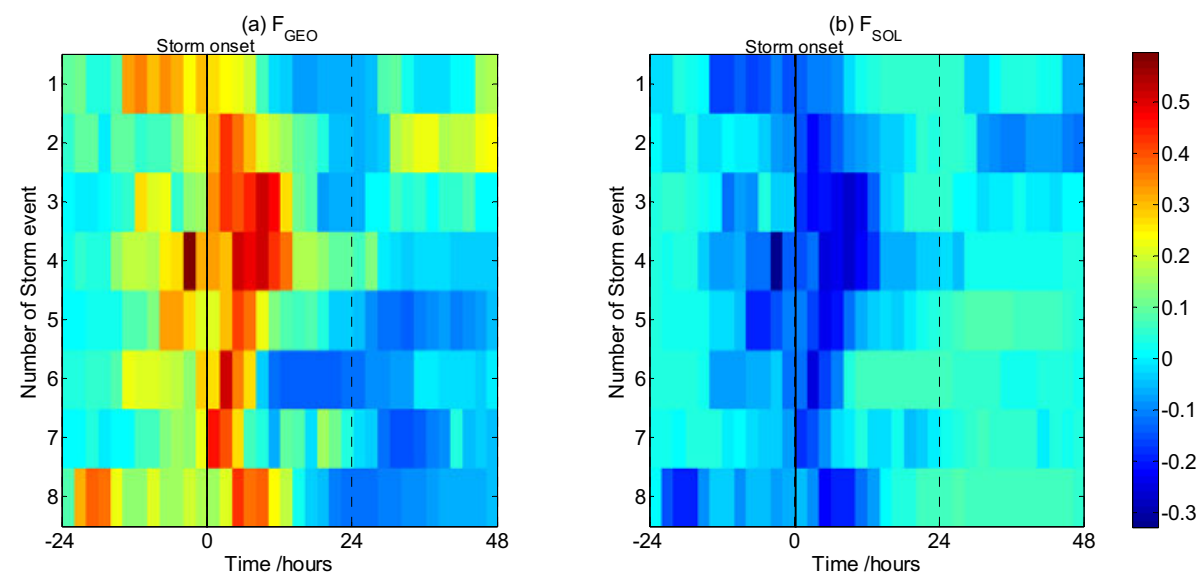

Fig. 8. Influence of geomagnetic activity $F_{\mathrm{GEO}}(\mathrm{a})$, and the integrated influence of geomagnetic activity and solar activity $F_{\text {SOL }}($ b). The number of the storm events is the same as the one in Fig. 7. The bold line is the time of storm onset.
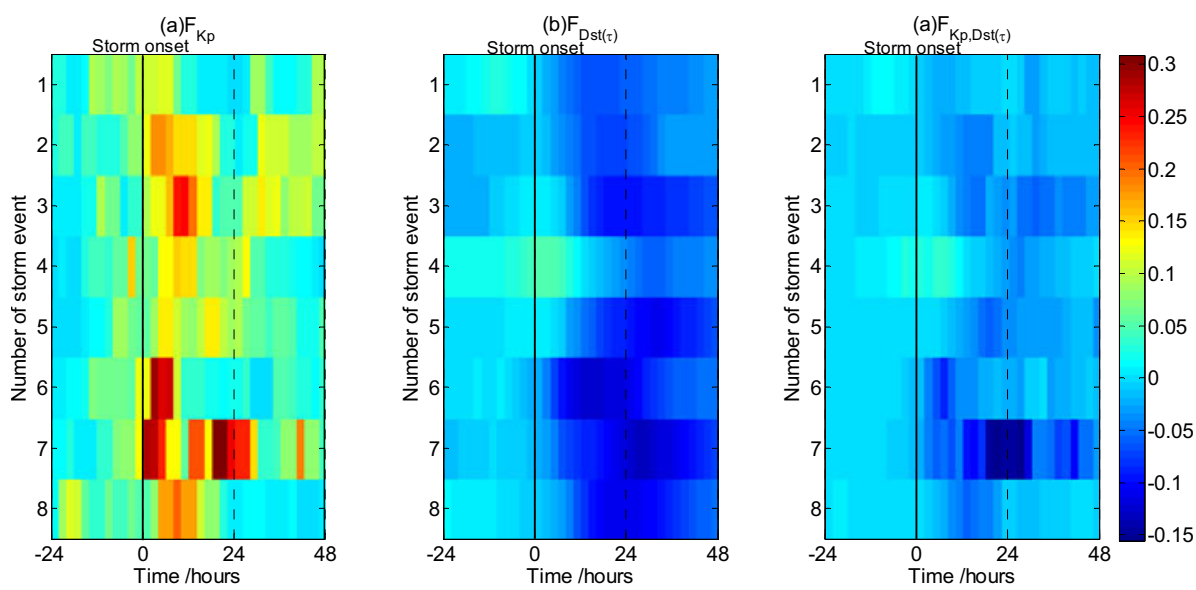

Fig. 9. Influence of geomagnetic $K p$ index $F_{K p}(\mathrm{a})$, influence of the time weighted $\operatorname{Dst}(\tau)$ index $F_{D s t(\Gamma)}(\mathrm{b})$, and the integrated influence $F_{K p, D s t(\Gamma)}(\mathrm{c})$. The number of storm events is the same as the one in Fig. 7. The bold line denotes the time of storm onset.

Fig. 9, we can see that all the impact values of $K p$ index are positive, while the values of two other components related with $\operatorname{Dst}(\tau)$ are almost always negative. For the $D s t$ index may occasionally be positive, $F_{D s t(\Gamma)}$ and $F_{K p, D s t(\Gamma)}$ may be positive. We can conclude that the current geomagnetic activity presented by $K p$ index will cause positive increase of ionosphere GEC. Several hours after storm onset, the $K p$ index will recover to a lower level, and then 
the accumulated geomagnetic activity effect presented by $\operatorname{Dst}(\tau)$ will cause the negative decrease of the GEC value. In Gulyaeva and Veselovsky (2012), the negative phase of GEC storm is found to occur synchronously with the decrease of the solar wind velocity and the outset of recovery of the Dst index and AE index. From the results of our researches it follows that the recovery of the Dst index is also closely related to the occurrence of negative phase of GEC storm. At the time of the recovery of the Dst index, the $K p$ index will generally decrease to a low value, which causes the positive component of GEC variation to be not significant, and then the negative component will dominate the GEC variation.

\section{CONCLUSION}

In this article, we analyzed the state and behavior of ionospheric GEC response to the geomagnetic storm by comparing quiet-time reference GEC value $\mathrm{GEC}_{\mathrm{QT}}$ with the GEC observables during 90 storm events in the years from 1999 to 2012. An empirical model was constructed and tested to present the variation characteristics of global ionosphere.

We concluded that two kinds of geomagnetic indices should be considered in the model. One is the $K p$ index which will reflect the current geomagnetic activity level, and the other is the time weighted $\operatorname{Dst}(\tau)$ index which will represent the accumulated influence of the geomagnetic activity in the previous period. Correlation analysis shows that time delay $\tau$ and time span should be 0.95 and previous 24 hours, respectively, for calculating $\operatorname{Dst}(\tau)$. Furthermore, the variation range of $R_{\mathrm{GEC}}$ shows a remarkable difference according to solar activity level. Hence, solar F10.7 index was also taken into account in the empirical model.

A linear model was constructed to present the GEC's response to geomagnetic storm activity. Results show that the model can reflect the positive phase and negative phase variation in GEC. Specifically, the component related with $K p$ index causes positive increase of the GEC, while $\operatorname{Dst}(\tau)$ will cause negative decrease of GEC several hours after the storm onset. The component related with solar $F 10.7$ index shows a counteractive effect with the component related with geomagnetic activity only.

Acknowledgments. This work is supported by the Fundamental Research Funds for the Central Universities (Grants No. 35832015084 and 35832015083 ) and the National Natural Science Foundation of China (Grant No. 41104025). 


\section{Appendix}

List of geomagnetic storm events analyzed in this paper

\begin{tabular}{|c|c|c|c|c|c|c|c|c|c|c|c|c|c|}
\hline$\stackrel{\vec{d}}{\grave{d}}$ & ڤે̊ & 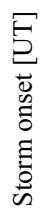 & 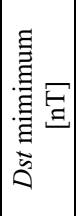 & 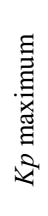 & 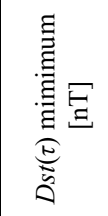 & 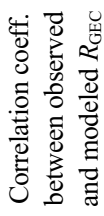 & $\stackrel{\Xi}{\circlearrowright}$ & & 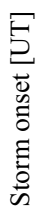 & 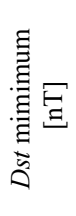 & 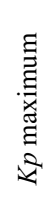 & 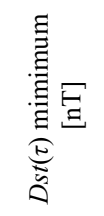 & 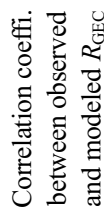 \\
\hline 1999 & 49 & 3 & -123 & 6.7 & -73.60 & 0.77 & 2002 & 274 & 5 & -174 & 7.3 & -107.16 & 0.93 \\
\hline 1999 & 59 & 22 & -94 & 5.7 & -49.97 & 0.88 & 2002 & 287 & 8 & -93 & 4.7 & -43.06 & 0.55 \\
\hline 1999 & 106 & 23 & -91 & 7.3 & -34.15 & 0.88 & 2003 & 169 & 5 & -141 & 6.7 & -58.89 & 0.30 \\
\hline 1999 & 203 & 1 & -48 & 4.7 & -21.78 & 0.69 & 2003 & 192 & 18 & -93 & 6.7 & -49.60 & 0.58 \\
\hline 1999 & 265 & 16 & -155 & 8.0 & -68.25 & 0.46 & 2003 & 229 & 23 & -148 & 7.3 & -85.55 & 0.92 \\
\hline 1999 & 294 & 19 & -228 & 8.0 & -90.95 & 0.72 & 2003 & 303 & 17 & -371 & 9.0 & -164.46 & 0.42 \\
\hline 1999 & 311 & 1 & -70 & 5.0 & -38.24 & 0.27 & 2003 & 324 & 8 & -422 & 8.7 & -167.09 & 0.70 \\
\hline 1999 & 320 & 10 & -79 & 4.3 & -30.10 & 0.19 & 2004 & 42 & 12 & -87 & 6.3 & -35.01 & 0.70 \\
\hline 2000 & 11 & 15 & -81 & 5.3 & -36.78 & 0.85 & 2004 & 96 & 12 & -60 & 6.3 & -40.19 & 0.69 \\
\hline 2000 & 22 & 14 & -97 & 6.3 & -46.77 & 0.93 & 2004 & 198 & 22 & -76 & 6.0 & -25.45 & 0.84 \\
\hline 2000 & 43 & 5 & -133 & 6.7 & -58.64 & 0.67 & 2004 & 204 & 15 & -91 & 7.0 & -44.61 & 0.75 \\
\hline 2000 & 97 & 17 & -262 & 8.7 & -123.18 & 0.51 & 2004 & 206 & 18 & -136 & 8.0 & -79.11 & 0.68 \\
\hline 2000 & 145 & 0 & -147 & 8.0 & -65.22 & 0.43 & 2004 & 209 & 2 & -151 & 8.7 & -87.81 & 0.85 \\
\hline 2000 & 197 & 14 & -301 & 9.0 & -128.64 & 0.83 & 2004 & 243 & 19 & -117 & 7.0 & -56.92 & 0.79 \\
\hline 2000 & 223 & 21 & -235 & 7.7 & -95.39 & 0.62 & 2004 & 312 & 18 & -374 & 8.7 & -140.26 & 0.80 \\
\hline 2000 & 225 & 2 & -225 & 7.7 & -95.57 & 0.74 & 2004 & 315 & 3 & -259 & 8.7 & -140.79 & 0.61 \\
\hline 2000 & 274 & 11 & -75 & 6.3 & -40.64 & 0.65 & 2005 & 7 & 18 & -93 & 7.7 & -39.02 & 0.74 \\
\hline 2000 & 278 & 6 & -166 & 7.7 & -102.97 & 0.77 & 2005 & 48 & 23 & -77 & 6.3 & -29.75 & 0.42 \\
\hline 2000 & 288 & 13 & -100 & 5.7 & -58.36 & 0.76 & 2005 & 135 & 3 & -229 & 8.3 & -85.42 & 0.42 \\
\hline 2000 & 302 & 21 & -127 & 6.0 & -59.64 & 0.44 & 2005 & 150 & 2 & -111 & 7.7 & -59.27 & 0.79 \\
\hline 2000 & 311 & 10 & -151 & 7.0 & -79.97 & 0.93 & 2005 & 163 & 11 & -100 & 7.3 & -46.05 & 0.86 \\
\hline 2000 & 331 & 21 & -80 & 6.3 & -35.94 & 0.35 & 2005 & 174 & 3 & -71 & 7.0 & -36.34 & 0.87 \\
\hline 2000 & 357 & 21 & -57 & 5.7 & -25.81 & 0.38 & 2005 & 191 & 6 & -92 & 6.3 & -41.26 & 0.65 \\
\hline 2001 & 78 & 12 & -146 & 7.3 & -87.48 & 0.92 & 2005 & 236 & 6 & -163 & 8.7 & -75.97 & 0.82 \\
\hline 2001 & 90 & 1 & -351 & 8.7 & -172.74 & -0.33 & 2005 & 243 & 8 & -119 & 7.0 & -52.15 & 0.79 \\
\hline 2001 & 101 & 14 & -236 & 8.3 & -103.78 & 0.84 & 2006 & 103 & 22 & -82 & 7.0 & -47.20 & 0.76 \\
\hline 2001 & 108 & 1 & -109 & 7.3 & -53.44 & 0.53 & 2006 & 231 & 13 & -79 & 6.0 & -36.44 & 0.81 \\
\hline 2001 & 112 & 5 & -102 & 6.3 & -55.37 & 0.90 & 2006 & 348 & 18 & -158 & 8.3 & -77.17 & 0.87 \\
\hline 2001 & 169 & 3 & -58 & 5.3 & -31.92 & 0.75 & 2009 & 203 & 3 & -81 & 5.7 & -37.50 & 0.75 \\
\hline 2001 & 229 & 12 & -92 & 7.0 & -35.81 & 0.67 & 2010 & 46 & 19 & -58 & 4.3 & -27.44 & 0.74 \\
\hline 2001 & 273 & 23 & -139 & 6.7 & -70.78 & 0.48 & 2010 & 148 & 22 & -84 & 5.3 & -36.64 & 0.68 \\
\hline 2001 & 276 & 6 & -166 & 7.0 & -82.37 & 0.64 & 2010 & 284 & 10 & -80 & 4.3 & -34.56 & 0.57 \\
\hline 2001 & 294 & 17 & -187 & 7.7 & -108.62 & 0.63 & 2010 & 362 & 12 & -50 & 4.0 & -18.80 & 0.40 \\
\hline 2001 & 301 & 3 & -157 & 6.7 & -75.09 & 0.80 & 2011 & 217 & 19 & -107 & 7.7 & -48.01 & 0.78 \\
\hline 2001 & 304 & 19 & -104 & 5.0 & -58.68 & 0.61 & 2011 & 252 & 13 & -69 & 5.7 & -27.74 & 0.54 \\
\hline 2001 & 309 & 23 & -288 & 8.7 & -141.30 & 0.60 & 2011 & 269 & 13 & -101 & 6.3 & -45.05 & 0.84 \\
\hline 2002 & 31 & 22 & -84 & 4.7 & -35.75 & -0.51 & 2011 & 297 & 19 & -132 & 7.3 & -47.96 & 0.86 \\
\hline 2002 & 33 & 2 & -84 & 4.7 & -35.75 & 0.11 & 2012 & 22 & 20 & -66 & 5.0 & -37.36 & 0.72 \\
\hline 2002 & 59 & 22 & -68 & 6.0 & -33.52 & 0.87 & 2012 & 67 & 4 & -78 & 6.0 & -36.51 & 0.59 \\
\hline 2002 & 107 & 11 & -127 & 7.3 & -76.47 & 0.68 & 2012 & 114 & 16 & -104 & 6.7 & -43.06 & 0.75 \\
\hline 2002 & 109 & 15 & -144 & 7.3 & -83.57 & 0.21 & 2012 & 169 & 2 & -78 & 6.3 & -36.18 & 0.67 \\
\hline 2002 & 131 & 10 & -105 & 6.7 & -50.77 & 0.85 & 2012 & 197 & 2 & -133 & 7.0 & -75.65 & 0.89 \\
\hline 2002 & 214 & 0 & -94 & 6.0 & -41.26 & 0.77 & 2012 & 274 & 23 & -133 & 6.7 & -52.52 & 0.79 \\
\hline 2002 & 246 & 21 & -109 & 6.3 & -51.68 & 0.69 & 2012 & 282 & 6 & -111 & 6.7 & -63.76 & 0.67 \\
\hline 2002 & 250 & 17 & -177 & 7.3 & -82.11 & 0.70 & 2012 & 318 & 20 & -105 & 6.3 & -48.10 & 0.89 \\
\hline
\end{tabular}




\section{References}

Afraimovich, E.L., E.I. Astafieva, S.V. Voeykov, B. Tsegmed, A.P. Potekhin, and J.L. Rasson (2006a), An investigation of the correlation between ionospheric and geomagnetic variations using data from the GPS and INTERMAGNET networks, Adv. Space Res. 38, 11, 2332-2336 , DOI: 10.1016/j.asr.2006.01.012.

Afraimovich, E.L., E.I. Astafyeva, and I.V. Zhivetiev (2006b), Solar activity and global electron content, Doklady Earth Sci. 409, 2, 921-924, DOI: 10.1134/ S1028334X06060195.

Afraimovich, E.L., E.I. Astafyeva, A.V. Oinats, Yu.V. Yasukevich, and I.V. Zhivetiev (2008), Global electron content: a new conception to track solar activity, Ann. Geophys. 26, 2, 335-344, DOI: 10.5194/angeo-26-335-2008.

Araujo-Pradere, E.A., and T.J. Fuller-Rowell (2000), A model of a perturbed ionosphere using the auroral power as the input, Geofis. Int. 39, 1, 29-36.

Araujo-Pradere, E.A., T.J. Fuller-Rowell, and M.V. Codrescu (2002), STORM: An empirical storm-time ionospheric correction model. 1. Model description, Radio. Sci. 37, 5, 3-1-3-12, DOI: 10.1029/2001RS002467.

Astafyeva, E.I., E.L. Afraimovich, A.V. Oinats, Yu.V. Yasukevich, I.V. Zhivetiev (2008), Dynamics of global electron content in 1998-2005 derived from global GPS data and IRI modeling, Adv. Space Res. 42, 4, 763-769, DOI: 10.1016/j.asr.2007.11.007.

Berdermann, J., C. Borries, M.M. Hoque, and N. Jakowski (2012), Forecast of total electron content over Europe for disturbed ionospheric conditions. In: 9th European Space Weather Week, 5-9 November 2012, Brussels, Belgium.

Bergeot, N., I. Tsagouri, C. Bruyninx, J. Legrand, J.-M. Chevalier, P. Defraigne, Q. Baire, and E. Pottiaux (2013), The influence of space weather on ionospheric total electron content during the $23 \mathrm{rd}$ solar cycle, J. Space Weather Space Clim. 3, A25, DOI: 10.1051/swsc/2013047.

Buonsanto, M.J. (1999), Ionospheric storms -a review, Space Sci. Rev. 88, 3-4, 563 601, DOI: 10.1023/A:1005107532631.

Forbes, J.M., S.E. Palo, and X. Zhang (2000), Variability of the ionosphere, J. Atmos. Sol.-Terr. Phys. 62, 8, 685-693, DOI: 10.1016/S1364-6826(00)00029-8.

Fuller-Rowell, T.J., M.V. Codrescu, R.J. Moffett, and S. Quegan (1994), Response of the thermosphere and ionosphere to geomagnetic storms, J. Geophys. Res. 99, A3, 3893-3914, DOI: 10.1029/93JA02015.

Gulyaeva, T.L., and I. Stanislawska (2008), Derivation of a planetary ionospheric storm index, Ann. Geophys. 26, 2645-2648, DOI: 10.5194/angeo-26-26452008.

Gulyaeva, T.L., and I.S. Veselovsky (2012), Two-phase storm profile of global electron content in the ionosphere and plasmasphere of the Earth, J. Geophys. Res. 117, A9, A09324, DOI: 10.1029/2012JA018017. 
Jakowski, N., S. Heise, S.M. Stankov, and K. Tsybulya (2006), Remote sensing of the ionosphere by space-based GNSS observations, Adv. Space Res. 38, 11, 2337-2343, DOI: 10.1016/j.asr.2005.07.015.

Jakowski, N., J. Mielich, C. Borries, L. Cander, A. Krankowski, B. Nava, and S.M. Stankov (2008), Large-scale ionospheric gradients over Europe observed in October 2003, J. Atmos. Sol.-Terr. Phys. 70, 15, 1894-1903, DOI: 10.1016/j.jastp.2008.03.020.

Lean, J.L., R.R. Meier, J.M. Picone, and J.T. Emmert (2011), Ionospheric total electron content: Global and hemispheric climatology, J. Geophys. Res. 116, A10, A10318, DOI: 10.1029/2011JA016567.

Li, S., J. Peng, W. Xu, and K. Qin (2013), Time series modeling and analysis of trends of daily averaged ionospheric total electron content, Adv. Space Res. 52, 5, 801-809, DOI: 10.1016/j.asr.2013.05.032.

Liu, L., W. Wan, B. Ning, and M. Zhang (2009), Climatology of the mean total electron content derived from GPS global ionospheric maps, J. Geophys. Res. 114, A6, A06308, DOI: 10.1029/2009JA014244.

Liu, L., W. Wan, Y. Chen, and H. Le (2011), Solar activity effects of the ionosphere: A brief review, Chin. Sci. Bull. 56, 12, 1202-1211, DOI: 10.1007/ s1 1434-010-4226-9.

Perrone, L., G. de Franceschi, and T.L. Gulyaeva (2001), The time-weighted magnetic indices $\operatorname{ap}(\tau), \operatorname{PC}(\tau), \operatorname{AE}(\tau)$ and their correlation to the southern high latitude ionosphere, Phys. Chem. Earth C 26, 5, 331-334, DOI: 10.1016/ S1464-1917(01)00008-3.

Pietrella, M., and L. Perrone (2008), A local ionospheric model for forecasting the critical frequency of the F2 layer during disturbed geomagnetic and ionospheric conditions, Ann. Geophys. 26, 2, 323-334, DOI: 10.5194/ angeo-26323-2008.

Prölss, G.W. (2006), Ionospheric F-region storms: Unsolved problems. In: Proc. Meeting RTO-MP-IST-056 "Characterising the Ionosphere”, Neuilly-surSeine, France, Paper No. 10, 10-1-10-20.

She, C., W. Wan, and G. Xu (2008), Climatological analysis and modeling of the ionospheric global electron content, Chin. Sci. Bull. 53, 2, 282-288, DOI: 10.1007/s11434-007-0519-z.

Stankov, S.M., N. Jakowski, K. Tsybulya, and V. Wilken (2006), Monitoring the generation and propagation of ionospheric disturbances and effects on Global Navigation Satellite System positioning, Radio Sci. 41, 6, RS6S09, DOI: $10.1029 / 2005 R S 003327$.

Stankov, S.M., K. Stegen, and R. Warnant (2010), Seasonal variations of storm-time TEC at European middle latitudes, Adv. Space Res. 46, 10, 1318-1325, DOI: 10.1016/j.asr.2010.07.017.

Trichtchenko, L., A. Zhukov, R. van der Linden, S.M. Stankov, N. Jakowski, I. Stanisławska, G. Juchnikowski, P. Wilkinson, G. Patterson, and A.W.P. Thomson (2007), November 2004 space weather events: Real time 
observations and forecasts, Space Weather 5, 6, S06001, DOI: 10.1029/ 2006SW000281.

Tsagouri, I., and A. Belehaki (2008), An upgrade of the solar-wind-driven empirical model for the middle latitude ionospheric storm-time response, J. Atmos. Sol.-Terr. Phys. 70, 16, 2061-2076, DOI: 10.1016/j.jastp.2008.09.010.

Tsagouri, I., A. Belehaki, G. Moraitis, and H. Mavromichalaki (2000), Positive and negative ionospheric disturbances at middle latitudes during geomagnetic storms, Geophys. Res. Lett. 27, 21, 3579-3582, DOI: 10.1029/ 2000 GL003743.

Wang, X., J.K. Shi, G.J. Wang, G.A. Zherebtsov, and O.M. Pirog (2008), Responses of ionospheric foF2 to geomagnetic activities in Hainan, Adv. Space Res. 41, 4, 556-561, DOI: 10.1016/j.asr.2007.04.097.

Wrenn, G.L. (1987), Time-weighted accumulations $\operatorname{ap}(\tau)$ and $\mathrm{Kp}(\tau)$, J. Geophys. Res. 92, A9, 10125-10129, DOI: 10.1029/JA092iA09p10125.

Wu, J., and P.J. Wilkinson (1995), Time-weighted magnetic indices as predictors of ionospheric behaviour, J. Atmos. Terr. Phys. 57, 14, 1763-1770, DOI: 10.1016/0021-9169(95)00096-K.

Xu, G., W. Wan, C. She, and L. Du (2008), The relationship between ionospheric total electron content (TEC) over East Asia and the tropospheric circulation around the Qinghai-Tibet Plateau obtained with a partial correlation method, Adv. Space Res. 42, 1, 219-223, DOI: 10.1016/j.asr.2008.01.007.

Zhao, B., W. Wan, L. Liu, and T. Mao (2007), Morphology in the total electron content under geomagnetic disturbed conditions: results from global ionosphere maps, Ann. Geophys. 25, 7, 1555-1568, DOI: 10.5194/angeo-251555-2007.

Zhao, B., W. Wan, L. Liu, K. Igarashi, M. Nakamura, L.J. Paxton, S.-Y. Su, G. Li, and Z. Ren (2008), Anomalous enhancement of ionospheric electron content in the Asian-Australian region during a geomagnetically quiet day, J. Geophys. Res. 113, A11, A11302, DOI: 10.1029/2007JA012987.

Received 22 June 2014 Received in revised form 27 October 2014 Accepted 19 January 2015 